\title{
Processo de produção e aproveitamento energético do biogás: uma revisão dos sistemas e tecnologias existentes no mercado
}

As fontes de energia renováveis contribuem para a melhoria do quadro socioambiental do planeta, ao passo que essas energias possuem um nível de poluição reduzido se comparadas com as fontes de energia fósseis. O biogás, produzido a partir da digestão anaeróbia da matéria orgânica presente em resíduos agropecuários e agroindustriais, representa uma fonte alternativa e renovável de energia cada vez mais utilizada em todo o mundo, havendo um potencial significativo de produção de biogás através destas biomassas. Assim, no presente artigo foi realizada uma revisão de literatura, desenvolvida por meio de legislação, livros e periódicos nacionais e internacionais, visando um detalhamento dos sistemas e técnicas de produção e aproveitamento energético do biogás disponíveis no mercado, desde o momento do pré-tratamento do resíduo até a sua conversão em energia. Diante desse estudo, pode-se observar que o biogás apresenta como alternativa energética no conjunto das renováveis, onde os benefícios gerados pelo aproveitamento, além de econômico, são sociais e ambientais, atendendo, desta maneira, as necessidades de tratamento dos resíduos de diversas origens, criando uma relação positiva entre desenvolvimento econômico e ambiental. Contudo, projetos para a geração de energia por meio do biogás demandam custos de implantação, operação e manutenção, mas ao todo demonstram que o processo de viabilidade do aproveitamento energético depende, substancialmente, da escala dos mesmos, para se tornarem autossustentável. Assim, esses resultados apenas pressupõem uma situação que poderá ser melhor avaliada com base em frequentes estudos, para aprimorar os processos, uma vez que cada situação em particular, é influenciada por características locais próprias.

\section{Biogas energy production and energy process: a review of the systems and technologies existing in the market}

\begin{abstract}
Renewable energy sources contribute to improving the socio-environmental picture of the planet, while these energies have a reduced level of pollution compared to fossil energy sources. Biogas, produced from the anaerobic digestion of organic matter present in agricultural and agroindustrial waste, represents an alternative and renewable source of energy increasingly used throughout the world, with a significant potential for biogas production through these biomasses. Thus, in this article a literature review was developed, developed through national and international legislation, books and periodicals, aiming at a detailed analysis of the biogas production systems and techniques available in the market, from the moment of pretreatment of the residue until its conversion into energy. In view of this study, it can be observed that biogas presents as an energetic alternative in the set of renewables, where the benefits generated by the use, besides economic, are social and environmental, thus meeting the needs of waste treatment of diverse origins, creating a positive relationship between economic and environmental development. However, projects for the generation of energy by means of biogas demand implementation, operation and maintenance costs, but in the whole they demonstrate that the process of viability of the energy utilization depends, substantially, on the scale of the same ones, to become self-sustaining. Thus, these results only presuppose a situation that can be better evaluated on the basis of frequent studies to improve the processes, since each particular situation is influenced by local characteristics.
\end{abstract}

Keywords: Renewable Energy Source; Sustainability; Electric Power; Biomass; Methane.

Topic: Sistemas de Energia Sustentável

Reviewed anonymously in the process of blind peer.
Received: $10 / 02 / 2019$

Approved: 25/03/2019
Ana Claudia Guedes Silva

Universidade Estadual do Oeste do Paraná, Brasil

http://lattes.cnpq.br/7655661739629134

anaa_guedess@hotmail.com

Gabriel de Menezes Trevisan

Universidade Tecnológica Federal do Paraná, Brasil

http://lattes.cnpq.br/7828220039083646

gabryelmt@hotmail.com
Referencing this:

SILVA, A. C. G.; TREVISAN, G. M.. Processo de produção e aproveitamento energético do biogás: uma revisão dos sistemas e tecnologias existentes no mercado. Revista Ibero Americana de Ciências Ambientais, v.10, n.2, p.197-210, 2019. DOI: http://doi.org/10.6008/CBPC2179-6858.2019.002.0017 


\section{INTRODUÇÃO}

Fontes de energia renováveis e de biocombustíveis recebem cada vez mais atenção como substitutos dos combustíveis fósseis. No entanto a sua implementação no mercado depende principalmente em tornar estas fontes mais competitivas. Uma opção para reduzir os custos dos biocombustíveis é utilizar os subprodutos gerados em determinados processos produtivos, como uma potencial fonte de energia, ao em vez de trata-los como resíduos sem valor econômico e ambiental (KOLESÁROVÁ et al., 2011).

Biomassa é toda e qualquer matéria bruta derivada de organismos vivos, incluindo culturas alimentares, gramíneas e plantas lenhosas, resíduos da agricultura e silvicultura, componentes orgânicos de resíduos urbanos, industriais e agroindustriais, ricos em carbono, que tem por objetivo principal a produção de energia (RODIONOVA et al., 2017).

A biomassa vegetal e animal possuem características semelhantes quando o assunto é aproveitamento energético. As principais formas de conversão energética são combustão direta (com ou sem processos físicos de secagem, classificação, compressão, corte/quebra), processos termoquímicos (gaseificação, pirólise, liquefação e transesterificação) ou de processos biológicos (digestão anaeróbia e fermentação) (PEREIRA et al., 2015).

A digestão anaeróbia é uma tecnologia que permite mitigar os efeitos adversos da disposição dos resíduos. Trata-se de um processo bioquímico que ocorre na ausência de oxigênio molecular livre, no qual um consórcio de microrganismos atua de forma sinérgica e protocooperativa (KOTHARI et al., 2014; RAJENDRAN et al., 2014) na conversão da matéria orgânica complexa (carboidratos, proteínas e lípidos) em metano $\left(\mathrm{CH}_{4}\right)$, compostos inorgânicos como o dióxido de carbono $\left(\mathrm{CO}_{2}\right)$, nitrogénio $\left(\mathrm{N}_{2}\right)$, amónia livre $\left(\mathrm{NH}_{3}\right)$, gás sulfídrico $\left(\mathrm{H}_{2} \mathrm{~S}\right)$ e traços de outros gases e ácidos orgânicos de baixo peso molecular, onde o efluente resultante, pode ser usado para fertirrigação como biofertilizante de solos.

Dessa forma, esse trabalho apresenta um levantamento bibliográfico dos processos e sistemas de geração de biogás, visando a questão ambiental, técnica, financeira e social em consonância com as soluções tecnológicas mais comumente utilizadas no mercado nacional e internacional para os sistemas de prétratamento da biomassa, biodigestão, armazenamento do biogás, transporte, purificação e aproveitamento elétrico.

\section{METODOLOGIA}

Este é um artigo de revisão literária, desenvolvida por meio de um levantamento bibliográfico em bases de dados eletrônicas sendo definidos descritores de assuntos visando uma consulta mais direcionada aos sistemas de biodigestão anaeróbia e de aproveitamento energético do biogás. As bases de dados pesquisadas foram legislação, livros e periódicos nacionais e internacionais disponíveis em acervos virtuais de revistas e bases de dados como SCIELO, LILACS, BIREME, BVS, Science Direct e Portal de Periódicos CAPES/MEC. As pesquisas eletrônicas aconteceram no período de fevereiro de 2018 a janeiro de 2019. 


\section{DISCUSSÃO TEÓRICA}

\section{Sistema de Biodigestão Anaeróbia}

A cadeia de produção e aproveitamento energético do biogás passa por até 6 etapas (Figura 1), que se inicia com o pré-tratamento, até seu aproveitamento energético, na geração de energia elétrica, onde vários sistemas devem ser cuidadosamente escolhidos e dimensionados para que a planta de biogás tenha boa eficiência na conversão da matéria orgânica em energia.

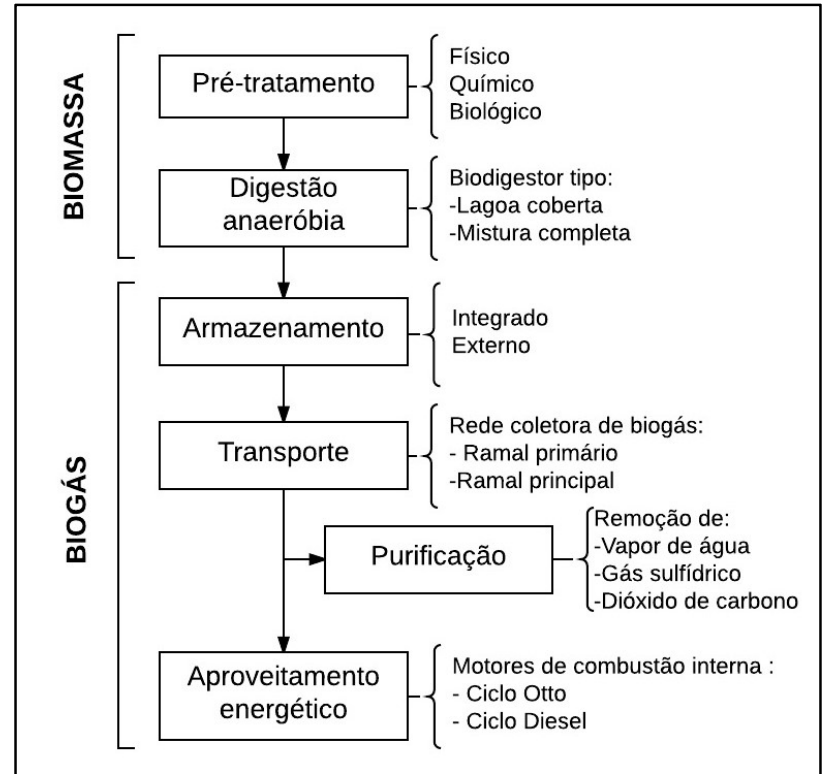

Figura 11: Processo de produção e conversão do biogás em energia.

O sistema de pré-tratamento da biomassa tem por objetivo tornar a biomassa mais susceptível à digestão anaeróbia. É um método complementar que pode aumentar o rendimento de metano do biogás e reduzir o teor de sólidos do efluente (CARLSSON et al., 2012; HENDRIKS et al., 2009) e/ou eliminar de outros componentes indesejados, como material inerte, solo, areia, entre outros, a fim de proteger dispositivos de transporte (bombas e tubulações) e até mesmo o assoreamento do biodigestor.

Pode-se classificar o pré-tratamento em físico, biológico, químico e/ou a combinação destes. Seus efeitos são complexos e geralmente dependem das características da biomassa e da tecnologia adotada. 0 pré-tratamento físico consiste na separação de fases, retirando sólidos indesejáveis como papéis, plásticos, pedaços de madeira, entre outros, e/ou reduzir o teor sólidos totais, aumentando a homogeneidade de um efluente. Os principais pré-tratamentos físicos são: gradeamento; tanque de equalização, decantação, peneiramento ou extrusão.

O gradeamento tem por objetivo remover os sólidos grosseiros. O mecanismo é composto por barras de metal posicionadas transversalmente, perpendiculares ou inclinadas, a montante do sistema de biodigestão. $\mathrm{O}$ espaçamento entre as barras vai depender do tamanho dos sólidos que se deseja remover. 0 tanque de equalização tem a função de uniformizar a vazão evitando a sobre carga de todo o sistema, como quando ocorre a limpeza mais intensa das instalações ou ainda quando ocorrem vazamentos. $O$ tanque pode ser construído de alvenaria ou apenas escavado no solo, desde seja impermeabilizado com membrana 
Polietileno de Alta Densidade (PEAD), com capacidade de armazenar no mínimo uma vez e meia o volume de efluente produzido num dia (CALZA et al., 2015). As possíveis sobre cargas devem ser enviadas ao biodigestor de forma contínua e não muito superior a vazão a usual de funcionamento.

Existem no mercado diversos modelos de peneiras para a separação contínua de líquidos e sólidos. Estes sistemas possuem alta eficiência na remoção de sólidos, a malha da peneira pode variar de acordo com as especificações de cada fabricante e a necessidade do cliente. Os modelos podem ser estáticos ou rotativos. O sistema estático é comumente utilizado para o pré-tratamento de resíduos agroindustriais. 0 efluente bruto ingressa pela parte superior da peneira na câmara de distribuição, desaguando através de um vertedouro. A fase líquida é coletada na parte interna da peneira enquanto que a fração sólida é separa na tela, deslocando-se para a borda e depositando-se no cesto coletor, promovendo a autolimpeza do sistema. A remoção do sólido do cesto coletor pode ser manual ou mecânica, com auxílio de um eixo helicoidal. A Figura 2 mostra um croqui do equipamento (a) e um sistema de coleta por eixo helicoidal (b).

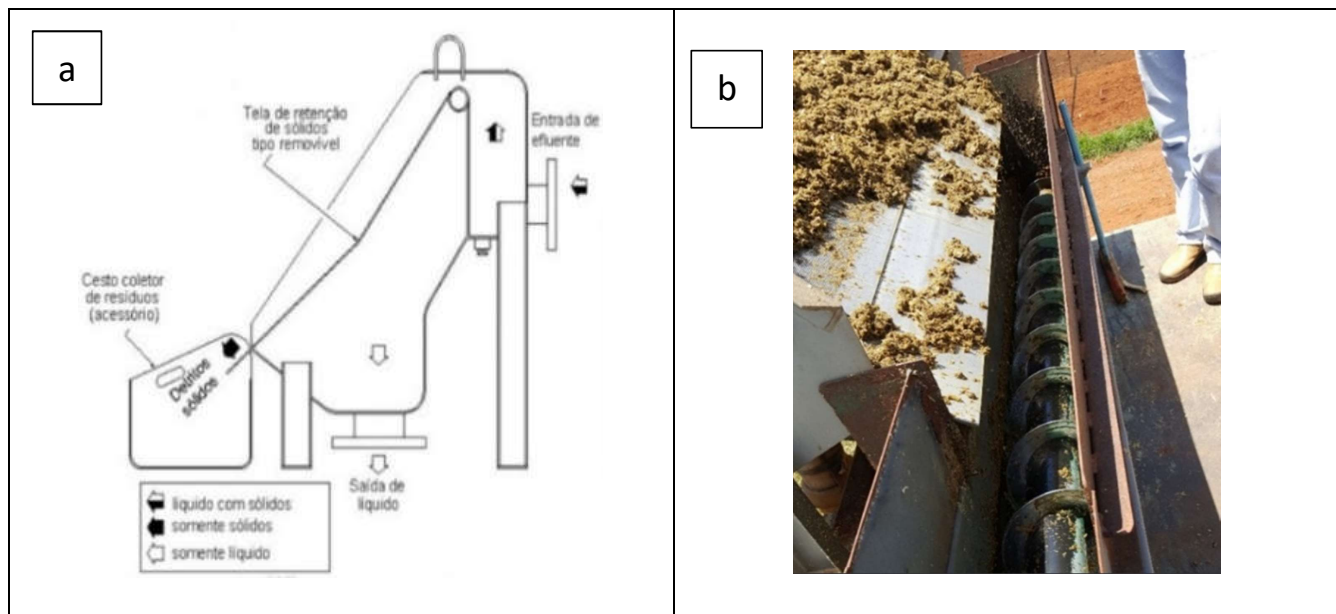

Figura 2: Desenho da peneira (a); mecanismo de coleta por eixo helicoidal (b).

A extrusora assim como as peneiras tem por objetivo a separação da fração sólida da líquida do efluente, entretanto a extrusora proporciona um material sólido com menor teor de umidade. Dependendo das características do equipamento e do efluente o processo de extrusão pode aumentar a biodegradabilidade da fração sólida, consequentemente a disponibilidade de nutrientes. O processo de extrusão consiste em um cilindro com um ou dois eixos helicoidal em seu interior, assim o cisalhamento gerado entre os eixos e a parede do cilindro proporciona tensão suficiente para triturar e moer a biomassa (Figura 3).

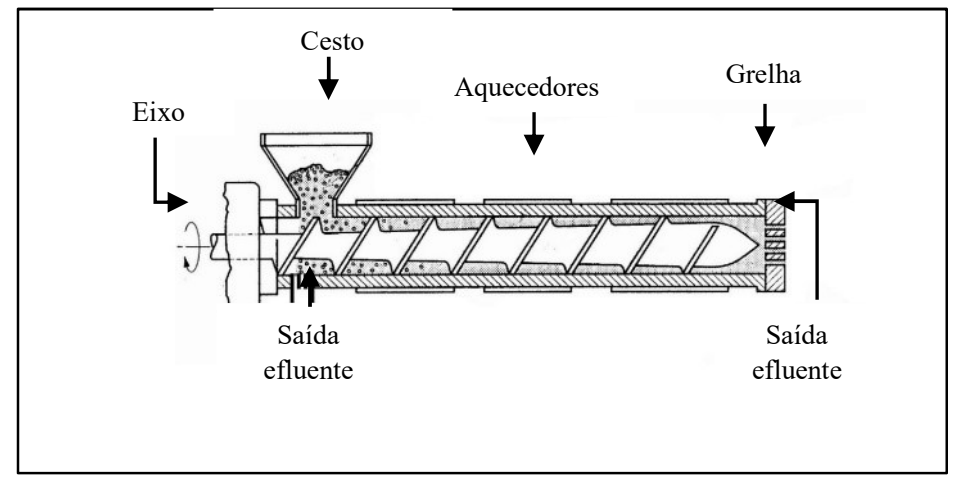

Figura 3: Processo de extrusão. 
O decantador realiza a separação da fase sólida e líquida, retendo os sólidos fixos e totais, reduzindo principalmente o assoreamento de biodigestores de fluxo pistonado. O decantador opera com vazão em regime laminar. Seu dimensionamento é em função do tempo de detenção necessário para retenção dos sólidos desejado. Um dos decantadores mais utilizado é o de palhetas, pois é de simples construção e operação, baixo custo e com boa eficiência de separação.

Já o pré-tratamento químico consistem em promover uma pré-hidrólise, ácida ou alcalina. A préhidrólise ácida tem alta eficiência principalmente na solubilização da lignina, entretanto está susceptível a formação de inibidores, podendo prejudicar a digestão anaeróbia (CARDONA et al., 2010; SINGHA et al., 2015). Já a pré-hidrólise alcalina aumenta a acessibilidade da celulose principalmente através da remoção da lignina e se mostra um método de baixo custo se comparado com o ácido, entretanto requer um tempo maior de retenção hidráulica (BALAT et al., 2008; MOOD et al., 2013).

O pré-tratamento biológico utiliza microrganismos para aumentar a disponibilidade de nutrientes do efluente, por meio da solubilização e remoção da lignina, como por exemplo, a compostagem e a préhidrólise com recirculação do efluente tratado pelo biodigestor. Este último método é bastante usado por ser de fácil operação e baixo custo, entretanto pode ser pouco eficiente em biomassa com alto teor de fibras, além de requerer um tempo maior de retenção hidráulica.

Nesse contexto a escolha do pré-tratamento ideal pode efetivamente aumentar a biodigestibilidade dos resíduos para a produção de biogás, uma vez que alguns sistemas podem quebrar e/ou solubilizar a estrutura lignocelulósica da biomassa, aumentando a digestão enzimática, consequentemente a produção de biogás.

\section{Sistema de Biodigestão Anaeróbia}

A tecnologia de biodigestão anaeróbia, na atualidade, é aplicada tanto no tratamento de resíduos agropecuários quanto agroindustriais e vem despertando grande interesse de uso, pois permite recuperar o potencial energético do resíduo na forma de biogás, realizando ao mesmo tempo o tratamento adequado do material residual. É uma tecnologia simples, cuja a principal preocupação é a manutenção das propriedades fermentativas da biomassa. Consiste basicamente numa câmara de fermentação, onde é processada a matéria orgânica por biodigestão anaeróbia e armazenado o biogás produzido.

Existe uma gama muito grande de modelos e configurações de biodigestores, porém mantendo quase o mesmo princípio de funcionamento. A escolha do sistema de biodigestão vai depender diretamente das característica físico-químicas da biomassa. A seguir serão apresentados os sistemas de lagoa coberta e mistura completa, sendo estes os sistemas mais difundidos. $\mathrm{O}$ biodigestor tipo lagoa coberta, conhecido também como canadense, consiste em uma câmara de biodigestão geralmente construída abaixo do nível do solo (escavada), tendo como características de projeto a dimensão retangular, profundidade limitada, fluxo pistonado e pouco instrumentado.

Possui paredes e cobertura revestidas por uma camada de geomembrana, constituída de Policloreto de Vinila (PVC) ou PEAD, podendo ser construído, basicamente, de material plástico. Apresenta construção 
bastante simples, porém possui menor durabilidade e está sujeito a acidentes, como no caso de haver perfuração da lona plástica, ou ruptura por ressecamento ou vendavais, ocasionando em vazamento de biogás.

Essa característica construtiva, de ser mais raso e longo, funciona como vantagem, pois garante maior exposição do biodigestor ao sol e ao solo, que atuam como reguladores de temperatura, operando em regime mesofílico. Entretanto em regiões frias, esse modelo de biodigestor, tem menor rendimento, uma vez que geralmente não conta sistema de controle de temperatura (WILLIAMS et al., 2012). Entre os benefícios desse sistema (Figura 4), destaca-se o menor custo de implantação e operação. Atualmente esse tipo de biodigestor é o mais difundido no mundo, e mais aplicado também no Brasil, sendo largamente utilizado em projetos agroindustriais com baixo teor de sólidos totais (FRIGO et al., 2015).
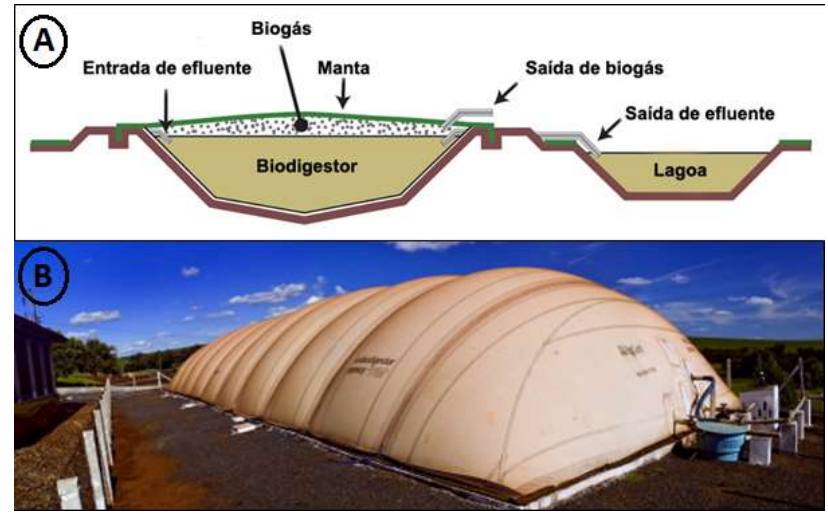

Figura 4: Esquema de funcionamento $(A)$ e representação $(B)$ de um biodigestor modelo lagoa coberta. Fonte: Adaptado de Williams et al. (2012).

\section{Biodigestor de mistura completa}

Já os biodigestores de mistura completa, denominados de CSTR (Continuous Stirred-tank Reactor), são caracterizados pelo ininterrupto processo de alimentação e alto grau de homogeneização do material em digestão, seja por agitadores mecânicos ou recirculação do efluente (GÜLZOW, 2013). Consiste em um tanque vertical, com fundo e paredes de concreto, podendo ter o reservatório total, parcial ou não enterrado. A presença de agitadores proporciona uma mistura completa do substrato, conferindo uma concentração equilibrada em todo o interior do reator, aumentando o contato matéria orgânica e microrganismos e consequentemente a biodegradabilidade e a produção de biogás (Figura 5).

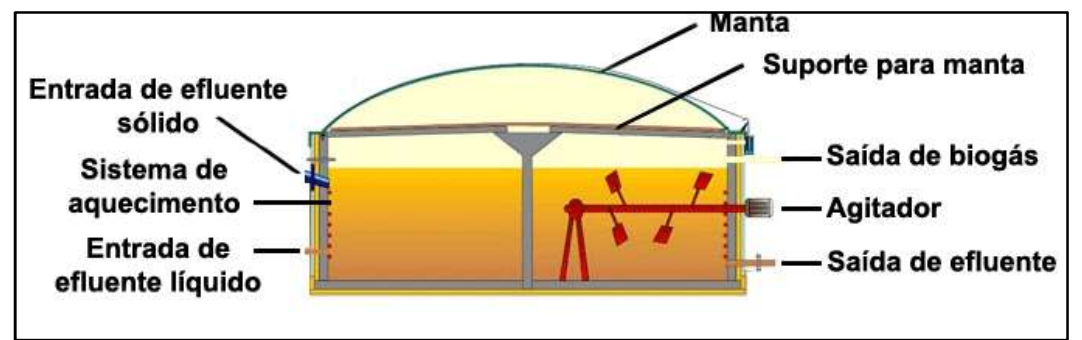

Figura 5: Representação de um biodigestor modelo mistura completa (CSTR). Fonte: Adaptado de Tesisat (2016).

Além da agitação, geralmente utiliza-se um sistema para aquecimento do substrato, de forma a elevar a temperatura interna do reator e garantir a operação na faixa mesofílica ou termofílica. Quando o 
biodigestor é construído abaixo da superfície do solo a perda de calor é menor (FEAM, 2015). Esse modelo de biodigestor é indicado para o tratamento de efluentes com elevada concentração de sólidos, pois proporciona a manutenção de uma biomassa estável no interior (PROBIOGÁS, 2015).

\section{Sistemas de armazenamento do biogás}

O gasômetro é um reservatório destinado ao armazenamento de biogás produzido no biodigestor, projetado para manter o equilíbrio entre a vazão de produção e a vazão de consumo de biogás. Desta forma, evitam-se oscilações e picos no volume de biogás, podendo manter sob pressão constante o biogás. Para que o uso desses gasômetros seja possível é necessário que eles sejam impermeáveis a gases, resistentes a pressão, raios UV, temperatura, intempéries e à ação das substâncias em contato. Devem ser testados antes do comissionamento e por regras de segurança precisam ser equipados com válvulas de alívio para altas e baixas pressões, a fim de evitar alterações graves e inadmissíveis na pressão no interior do recipiente (GÜLZOW, 2013).

O objetivo, portanto, desses reservatórios é permitir que o desempenho do sistema de conversão do biogás em energia não sofra influência pela oscilação da produção de gás, garantindo uma vazão constante. Para dimensionar o volume dos reservatórios é necessário relacionar a demanda de biogás ao seu uso final, ou seja, o volume do gasômetro é em função da demanda do sistema de conversão em energia. Deve-se armazenar, pelo menos, $25 \%$ da produção diária e recomenda-se estimar um volume equivalente a produção de 1 a 2 dias (GÜLZOW, 2013). A Equação 1 é utilizada para calcular o valor do volume do gasômetro. Esta equação não se aplica a sistemas pressurizados.

$$
V g=P d * P a
$$

\section{(Equação 1)}

em que: Vg: volume do gasômetro $\left(\mathrm{Nm}^{3}\right)$; Pd: produção de biogás diária ( $\left.\mathrm{Nm}^{3} / \mathrm{dia}\right)$; Pa: produção acrescida (dias).

Assim, os sistemas de armazenamento são divididos em dois tipos: integrado e/ou armazenamento externo.

Os sistemas de armazenamento integrado utilizam a cúpula de lona para estocar o gás no próprio biodigestor ou em um reservatório de biofertilizante. Para utilizar este sistema é necessário montar uma armação de suporte no reservatório, sobre a qual a lona se apoiará quando não houver volume de gás, e consequentemente, a lona inflará conforme o nível de biogás (GÜLZOW, 2013). A grande vantagem deste tipo de armazenamento é a redução significativa dos custos de investimento.

Dentre os sistemas de armazenamento integrado têm-se o gasômetro de dupla-membrana e o gasômetro falso. $\mathrm{O}$ gasômetro de dupla-membrana é formado basicamente por uma membrana externa, uma membrana interna e um sistema de cinta opcional com um poste central. A membrana interna tem por função armazenar o gás e a membrana externa defini o formato do armazenador de biogás e absorve as cargas de vento (RODIONOVA et al., 2017).

O gasômetro falso é constituído por uma membrana externa e um sistema de ancoragem integrado ao biodigestor. Esta membrana externa tem por funções armazenar o gás e absorver as cargas de vento 
(ERYASAR et al., 2012). O gasômetro falso tem por vantagem o baixo custo de implantação, a projeção conforme os requisitos locais e necessidades individuais, porém o problema é alta manutenção. Em contrapartida, o gasômetro de dupla-membrana possui como principal vantagem à baixa manutenção. A desvantagem deste modelo é o alto custo de implantação.

Já o sistema de armazenamento externo são gasômetros construídos em anexo ao biodigestor, podendo ou não, ser abrigados em um edifício adequado ou equipado com uma segunda lona. Existem diversas formas de se projetar o gasômetro externo em como: padrão, travesseiro, cúpula e os cilindros. Estes sistemas são pouco utilizados quando o aproveitamento do biogás é elétrico.

\section{Sistema de transporte de Biogás}

Para realizar o aproveitamento energético do biogás se faz necessário conectar o ponto de produção, o gasômetro, com o de consumo, por exemplo, um motogerador, por meio de uma rede coletora de biogás. Podendo ainda conectar vários pontos de produção a um ou mais consumidores. Uma rede coletora de biogás pode ser composta por ramais primários e principais. O ramal primário é a denominação dada à rede de tubulação e ao conjunto de acessórios que conduzirão o biogás produzido nas propriedades até o ramal principal. A tubulação se inicia na saída da unidade de compressão, que comprime o biogás e mantem a rede coletora pressurizada, e terminam na conexão com o ramal principal, que interliga vários produtores (PROBIOGÁS, 2015).

Já ramal principal corresponde à rede de tubulação e ao conjunto de acessórios que receberão o biogás dos ramais primários e o conduzirão até determinado ponto consumidor (HENGEVELD et al., 2016). Quando o biogás é produzido e consumido na mesma propriedade recebe a denominação de rede coletora de biogás e geralmente não possui uma unidade de compressão e sim apenas um soprador de biogás.

Em relação as características técnicas, as redes coletoras de biogás ainda não possuem qualquer regulamentação no Brasil, deste modo, para o planejamento, implantação e operação deste tipo de gasoduto são utilizadas normas aplicadas ao gás natural (GN). Para utilização destas normas em projetos de biogás é necessário à realização de adaptações, sendo possível fazer adequações que diminuem o custo da implantação, como exemplo, a alteração do material da tubulação, de aço inox para PEAD. O traçado da rede coletora de biogás é definido a partir dos seguintes critérios técnicos: topografia, classe e uso do solo, localização dos pontos de produção e consumo do biogás, características de operação do condomínio de agroenergia (WOLF et al., 2000).

O gasoduto deve ser preferencialmente acondicionado em uma vala com o fundo compactado manualmente, a tubulação deverá ser envolvida em meio a uma camada de areia grossa ou terra isenta de corpos estranhos e posteriormente compactada. Esta camada de areia deverá ter a espessura suficiente apenas para cobrir completamente a tubulação, cujo objetivo é proteger a rede coletora de biogás e proporcionar o reestabelecimento da paisagem original. 


\section{Sistemas de Purificação do Biogás}

O biogás in natura contém na sua composição elementos que podem reduzir a vida útil de componentes mecânicos, fazendo necessário a utilização de sistemas purificação que removam impurezas presentes no biogás (Figura 6). A purificação também aumenta o poder calorífico do biogás, podendo obter até o biometano, que é um biocombustível com propriedades semelhantes ao do gás natural, ou seja, é possível emprega-lo nos mesmos usos que o gás natural, como no abastecimento veicular.

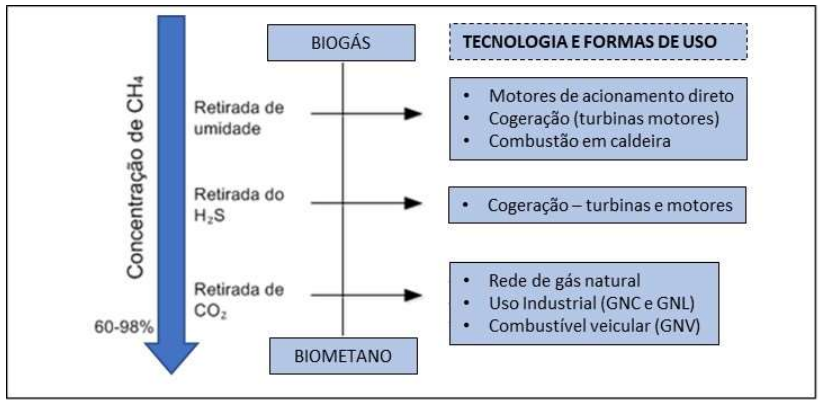

Figura 6: Cadeia de purificação de biogás. Fonte: Probiogás (2015).

A necessidade de remoção de gases presentes no biogás varia de acordo com a finalidade da utilização do biogás, conforme aprestando na Tabela 1. A norma brasileira ANP Nº8/2015, da Agência Nacional de Petróleo, pode ser tomada como exemplo das concentrações limites para que o biometano. A Tabela 2 traz sua especificação técnica.

Tabela 1: Necessidade de remoção de componentes do biogás por aplicação.

\begin{tabular}{|l|c|c|c|}
\hline \multicolumn{1}{|c|}{ Aplicação } & $\mathbf{H}_{\mathbf{2}} \mathbf{S}$ & $\mathrm{CO}_{\mathbf{2}}$ & $\mathbf{H}_{\mathbf{2}} \mathbf{O}$ \\
\hline Caldeira a gás para aquecimento & $<1000 p p m$ & Não & Não \\
\hline Utilização em cozinha & $\mathrm{Sim}$ & Não & Não \\
\hline Veículos a gás & $\mathrm{Sim}$ & $\mathrm{Sim}$ & $\mathrm{Sim}$ \\
\hline Rede de gás natural & $\mathrm{Sim}$ & $\mathrm{Sim}$ & $\mathrm{Sim}$ \\
\hline
\end{tabular}

Fonte: Adaptada de Frare et al. (2009).

Tabela 2: Especificação de parâmetros para o Biometano.

\begin{tabular}{|l|c|c|}
\hline \multicolumn{1}{|c|}{ Característica } & Unidade & Limite \\
\hline Metano (mínimo) & $\%$ mol. & 96,5 \\
\hline Oxigênio (máximo) & $\%$ mol. & 0,5 \\
\hline $\mathrm{CO}_{2}$ (máximo) & $\% \mathrm{~mol}$. & 3,0 \\
\hline $\mathrm{CO}_{2}+\mathrm{O}_{2}+\mathrm{N}_{2}$ (máximo) & & 3,5 \\
\hline Enxofre Total (máximo) & $\mathrm{mg} / \mathrm{m}^{3}$ & 70 \\
\hline Gás Sulfídrico ( ${ }_{2} \mathrm{~S}$ ) (máximo) & $\mathrm{mg} / \mathrm{m}^{3}$ & 10 \\
\hline Ponto de orvalho de água a 1atm & oC & -45 \\
\hline
\end{tabular}

Fonte: Adaptada de ANP (2015).

Na saída do biodigestor o biogás está saturado com vapor de água, que ao condensar pode bloquear a passagem do gás, além de reduzir o poder calorífico e acelerar o processo de corrosão dos sistemas de conversão em energia, fazendo-se essencial a secagem do biogás. Existem diversos métodos para remoção do vapor de água, como a condensação, adsorção e absorção.

A retirada do gás sulfídrico $\left(\mathrm{H}_{2} \mathrm{~S}\right)$ também se faz necessária, pois este composto apresenta propriedades corrosivas, além de ser um gás altamente tóxico e com odor desagradável. A remoção deste 
composto do biogás é altamente necessário e pode ser realizado de diversas maneiras e em diferentes etapas de produção.

Os principais sistemas para a remoção de ácido sulfídrico são: dessulfurizarão biológica no biodigestor ou externa, lavagem bioquímica; dessulfurizarão química e com carvão ativado. Assim a robustez do sistema de purificação dependerá da forma de aproveitamento do biogás, que pode exigir pouca ou nenhuma tolerância a certos componentes, como a água $\left(\mathrm{H}_{2} \mathrm{O}\right)$, o gás sulfídrico $\left(\mathrm{H}_{2} \mathrm{~S}\right)$ e o dióxido de carbono $\left(\mathrm{CO}^{2}\right)$. Visando, neste trabalho, a aplicação do biogás como energia elétrica, será tratado a seguir apenas os sistemas mais utilizados de remoção de vapor de água e do $\mathrm{H}_{2} \mathrm{~S}$.

A secagem por condensação utiliza um processo baseado na separação do condensado por resfriamento forçado, através de trocadores de calor, onde a mistura atinge sua temperatura de saturação alterando o estado de vapor para líquido. Geralmente o resfriamento do biogás é feito na tubulação de gás e o condensado é recolhido em purgadores de vapor. Um resfriamento adicional pode ser obtido através da água fria. Este método permite atingir pontos de orvalho de 3 a $5^{\circ} \mathrm{C}$, podendo atingir uma redução do vapor d'água com volume original de 3,1\%, para até $0,15 \%$ em volume. A extração do condensado pode ser ainda mais eficiente se o gás for comprimido previamente (GÜLZOW, 2013).

Como vantagem, este processo permite a aplicação em todos os sistemas de geração de biogás e é indicado para qualquer fluxo volumétrico, além de remover parte de gases solúveis em água, aerossóis e sixolanos. Já a secagem por adsorção visando a redução do $\mathrm{H}_{2} \mathrm{~S}$, o fluido fica aderido à superfície do material adsorvente, comumente utilizado o carvão ativado. O biogás então é forçado à passa por colunas, pressurizadas, contendo o meio adsorvente.

Este método pode ser utilizado, por exemplo, para ajustar o grau de umidade do biometano posterior à secagem por resfriamento, garantindo maior eficiência, sendo possível atingir pontos de orvalho de até $90^{\circ} \mathrm{C}$ proporcionando que este biogás tenha características equivalentes ao gás natural. Tem como vantagem a possibilidade de regeneração dos materiais adsorventes e como desvantagem, a operação das colunas deve ocorrer sob pressão de 6 a 10 bar (BALSAMO et al., 2016).

\section{Sistemas de aproveitamento elétrico}

As tecnologias mais utilizadas para geração de energia elétrica a partir do biogás são as microturbinas a gás e os motores de combustão interna (ciclo Otto e ciclo Diesel). Os motores de combustão interna são motores térmicos que tem por finalidade transformar energia calorífica em energia mecânica, através da queima de combustível e vapor dentro de um cilindro (GOMES et al., 2017). Eles são os mais utilizados para geração de energia elétrica a partir do biogás, podendo ser a ignição a centelha - ciclo Otto ou a ignição a compressão - ciclo Diesel.

O motor gerador ciclo Otto é a tecnologia mais utilizada atualmente e seu funcionamento ocorre a partir da mistura de ar com o combustível no cilindro, onde ocorre a explosão devido à ignição e compressão da mistura. A força da explosão é transferida ao pistão, que por sua vez desce e sobe em um movimento 
periódico. Esse movimento é transformado em movimento rotativo e ligado ao eixo do gerador (BERTINATTO et al., 2017).

A principal modificação está no fornecimento de ar e no processo de mistura do ar ao biogás, substituindo o carburador de um motor, que utiliza combustível em estado líquido, em um dispositivo arbiogás, assim o motor é controlado através da quantidade de biogás que é abastecido. Para otimizar este tipo de sistema é desejável um aumento na razão de compressão, que possibilita um menor consumo de combustível e uma maior potência. Isto ocorre pelo fato do biogás apresentar altas temperaturas de autoignição, aumentando seu poder antidetonante e permitindo o aumento da taxa de compressão.

Para esse tipo de motores, a mistura ar-combustível introduzida no cilindro é comprimida e tem sua frente de chama iniciada por uma centelha elétrica, produzida pelo sistema de ignição. E devido às características do metano, é apropriada a introdução de uma vela de ignição de maior grau térmico, pela alta temperatura de combustão do metano.

De qualquer forma, a transformação de um motor Otto operado a combustível líquido para biogás terá como consequência uma produção de energia inferior. Isso ocorre porque a eficiência volumétrica do sistema é reduzida. Essa redução é devida ao fato de que em um mesmo volume de mistura, um combustível líquido possui maior energia que a mistura de um combustível gasoso (ROSSETTO et al., 2014).

Mesmo estando em estado gasoso e não precisando do processo de vaporização, o biogás ocupa maior porção em volume de mistura admitida do que ocuparia um combustível líquido. Devido a essa limitação em volume na quantidade de ar admitido durante o processo, torna-se necessária a utilização de biogás com elevado grau de pureza, pois grandes porções de $\mathrm{CO}_{2}$, contidos em uma porção de biogás não purificado, também reduzirão o rendimento volumétrico.

Além de todas estas características citadas, o biogás possui uma velocidade de combustão mais lenta que a gasolina e o álcool, e por isso o uso do gás deve ter teor mínimo de $45 \%$ de metano (QIAN et al., 2017). Já o motor gerador ciclo diesel são com ignição a compressão e trabalham sob o princípio do motor a diesel, podendo ser modificados para o uso com biogás por duas diferentes maneiras: operação bicombustível com ignição por injeção de combustível piloto, e funcionamento a gás somente com ignição por faísca (QIAN et al., 2017).

Para operações do tipo bicombustível, é necessário sempre que, juntamente com o biogás, seja adicionado diesel, o que acarreta em uma manutenção maior do sistema. Este tipo de configuração possui algumas limitações, como o fato de que não é possível dar partida sem o fornecimento de diesel para ignição porque pode-se ter um superaquecimento dos jatos de injeção de combustível quando o percentual de diesel estiver em valores menores que 15\% do fluxo total de combustível (SUZUKI et al., 2011).

A dosagem é ajustada de forma que a fração de óleo de ignição seja de aproximadamente de $2 \%$ $5 \%$ do poder de combustão introduzido. Como a quantidade de óleo de ignição injetado é relativamente pequena, existe o risco de carbonização e obstrução precoce dos bicos injetores uma vez que eles não são refrigerados, como também a emissão de poluentes fora dos limites estabelecidos e vida útil curta do motor (GÜLZOW, 2013). 
Já os sistemas de ciclo diesel operados somente a gás exigem que sejam adaptados, e para isto é necessário remover a bomba injetora, inserir a válvula borboleta de controle do fluxo, reduzir a taxa de compressão, entre outros. Essa adaptação é complexa, contudo, parece ser a mais adequada do ponto de vista técnico e econômico dos demais motores movidos a biogás.

Os projetos aplicados a motores ciclo diesel, na maioria, já preveem baixas velocidades de rotação e altas taxas de compressão. Desta forma, o aproveitamento termodinâmico destes motores mostra-se mais vantajoso do que motores ciclo Otto que operam com o mesmo combustível gasoso (FIGUEIREDO et al., 2012).

\section{CONCLUSÕES}

Diante do exposto ao longo desta pesquisa, fica evidente que o tema pesquisado é de suma importância, uma vez que o estudo do aproveitamento energético do biogás auxilia na promoção de ações que contribuam para a melhora da qualidade de vida da população, bem como na proteção e conservação dos recursos naturais do meio ambiente.

Assim, medidas alternativas para geração de energia, cada vez mais limpas e viáveis, estão sendo mais exploradas, devido à necessidade de assegurar a matriz energética de forma sustentável. A produção de biogás, a partir de resíduos agropecuários e agroindústrias, vem a calhar, contribuindo para melhoria de dois sistemas, o da disposição de resíduos e também podendo ser utilizado como fonte renovável de energia.

Além disso, a crescente busca da sociedade pela sustentabilidade, fortalece o uso das fontes de energias renováveis e a reutilização desses resíduos como alternativa energética, destacando-se assim, os biodigestores como uma solução para o tratamento de resíduos sólidos orgânicos de diversas origens. $\mathrm{O}$ biogás se apresenta como alternativa energética no conjunto das renováveis, onde os benefícios gerados pelo aproveitamento, além de econômico, são sociais e ambientais, atendendo, desta maneira, as necessidades de tratamento dos resíduos, criando uma relação positiva entre desenvolvimento econômico e ambiental.

Contudo, os projetos para a geração de energia por meio do biogás demandam custos de implantação, operação e manutenção, mas ao todo demonstram que o processo pode ser viável pois, considera-se autossustentável. Assim, esses resultados apenas pressupõem uma situação que poderá ser melhor avaliada com base em frequentes estudos, para aprimorar os processos, uma vez que cada situação em particular, é influenciada por características locais próprias.

\section{REFERÊNCIAS}

ANP. Agência Nacional do Petróleo Gás Natural e Biocombustíveis. Resolução ANP n.8: Estabelece a especificação do Biometano contida no Regulamento Técnico ANP no 1/2015, parte integrante desta Resolução. Diário Oficial da União, 2015.

BALAT, M.; BALAT, H.; OZ, C.. Progress in Bioethanol Processing. Progress in Energy and Combustion Science, v.34, n.5, p.551-573, 2008. DOI:

http://doi.org/10.1016/i.pecs.2007.11.001

BALSAMO, M.; CIMINO, S.; FALCO, G.; ERTO, A.; LISI, L.. ZnO$\mathrm{CuO}$ supported on activated carbon for $\mathrm{H} 2 \mathrm{~S}$ removal at room temperature. Chemical Engineering Journal, v.304, p.399407, 2016. DOI: http://doi.org/10.1016/i.cej.2016.06.085 
BERTINATTO, R.; FRIEDRICH, L.; GURGACZ, F.; PAZUCH, F. Analysis of lubricant oil contamination and degradation and wear of a biogas-fed otto cycle engine. Acta Scientiarum. Technology, v.39, n.4, p.409-416, 2017. DOI: http://doi.org/10.4025/actascitechnol.v39i4.29458

CALZA, L. F.; LIMA, C. B.; NOGUEIRA, C. E. C.; SIQUEIRA, J. A. C.; SANTOS, R. F.. Avaliação dos custos de implantação de biodigestores e da energia produzida pelo biogás. Revista Engenharia Agrícola, Jaboticabal, v.35, n.6, p.990-997, 2015. DOI: http://dx.doi.org/10.1590/1809-4430-

Eng.Agric.v35n6p990-997/2015

CARDONA, C. A.; QUINTERO, J. A.; PAZ, I. C.. Production of Bioethanol from Sugarcane Bagasse: Status and Perspectives. Bioresource Technology, v.101, n.13, p.47544766, 2010. DOI: http://doi.org/10.1016/i.biortech.2009.10.097

CARLSSON, M.; LAGERKVIST, A.; MORGAN-SAGASTUME, F. The effects of substrate pre-treatment on anaerobic digestion systems: A review. Waste Management, v.32, n.9, p.1634-1650, 2012. DOI: http://doi.org/10.1016/j.wasman.2012.04.016

ERYASAR, A.; KOCAR, G.. Gasometer with the function of gas purification for the biogas systems in the rural area. Energy Education Science and Technology, Part A, Energy Science and Research, v.28, n.2, p.657-668, 2012.

FIGUEIREDO, F. L.; FERNANDES, F.; PETRUCCI, A. L.; FURINI FILHO, R.; MARSURA, M.. Produção de energia elétrica através da biomassa em sistema de gaseificação concorrente e grupo gerador com capacidade de 50 kVA. Semina: Ciências Exatas e Tecnológicas, v.32, n.2, p.165-174, 2012. DOI: http://doi.org/10.5433/1679-0375.2012v33n2p165

FRARE, L. M.; GIMENES, M. L.; PEREIRA, N. C.. Processo para remoção de ácido sulfídrico de biogás. Revista Engenharia Sanitaria e Ambiental, v.14, n.2, p.167-172. 2009. DOI: http://doi.org/10.1590/S1413-41522009000200004

FRIGO, K. D. A.; FEIDEN, A.; GALANT, N. B.; SANTOS, R. F.; MARI, A. G.; FRIGO, E. P.. Biodigestores: seus modelos e aplicações. Acta Iguazu, Cascavel, v.4, n.1, p.57-65, 2015.

FEAM. Fundação Estadual do Meio Ambiente. Guia técnico ambiental de biogás na agroindústria. Federação das Indústrias do Estado de Minas Gerais, Cooperação Alemã para o Desenvolvimento Sustentável (GIZ), Belo Horizonte, 2015.

GOMES, G. V.; SUDA, S. J.; ROSA, A. P.; RODRIGUES, F. A.. Estudo da produção de energia elétrica a partir de biogás com e sem purificação de estação de tratamento de esgoto. The Journal of Engineering and Exact Sciences, v.3, n.7, p.899-919, 2017. DOI:

http://doi.org/10.18540/icecvl3iss7pp0899-0919

GÜLZOW, O.. Guia Prático do Biogás: Geração e Utilização. 5 ed. Gülzow-prüzen: Fachagentur Nachwachsende Rohstoffe E. v., 2013.

HENDRIKS, A. T. W. M.; ZEEMAN, G.. Pretreatments to enhance the digestibility of lignocellulosic biomass. Bioresource Technology, v.100, n.1, p.10-18, 2009. DOI: http://doi.org/10.1016/j.biortech.2008.05.027
HENGEVELD, E. J.; BEKKERING, J.; VAN GEMERT, W. J. T.; BROEKHUIS, A. A.. Biomass and Bioenergy, Biogas infrastructures from farm to regional scale, prospects of biogas transport grids. Biomass and Bioenergy, v.86, p.4352, 2016. DOI:

http://doi.org/10.1016/j.biombioe.2016.01.005

KOLESÁROVÁ, N.; HUTNAN, M.; BODIK, I.; SPAKOVÁ, V.. Utilization of Biodiesel By-Products for Biogas Production. Journal of Biomedicine and Biotechnology, v.2011, n.11, 2011.

KOTHARI R, PANDEY A. K; KUMAR S; TYAGI V. V; TYAGI S. K. Different aspects of dry anaerobic digestion for bio-energy: An overview. Renewable and Sustainable Energy Reviews, v.39, p.174-195, 2014. DOI: http://doi.org/10.1016/i.rser.2014.07.011

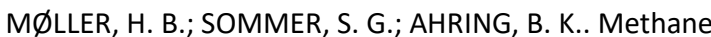
productivity of manure, straw and solid fractions of manure. Biomass and Bioenergy, v.26, p.485-495, 2004.

MOOD, S. H.; GOLFESHAN, A. H.; TABATABAEI, M.; JOUZANI, G. S.; NAJAFI, G. H.; GHOLAMI, M.; ARDJMAND, M.. Lignocellulosic biomass to bioethanol, a comprehensive review with a focus on pretreatment. Renewable and Sustainable Energy Reviews, v.27, p.77-93, 2013. DOI: http://doi.org/10.1016/i.rser.2013.06.033

PEREIRA, M. S.; GODOY, T. P.; GODOY, L. P.; BUENO, W. P.; WAGNER, R. S.. Energias renováveis: biogás e energia elétrica provenientes de resíduos de suinocultura e bovinocultura na UFSM. Revista Eletrônica em Gestão, educação e Tecnologia ambiental, v.19, n.3, p.239-247, 2015.

PROBIOGÁS. Tecnologias de digestão anaeróbia com relevância para o Brasil: substratos, digestores e uso de biogás. Projeto Brasil: Alemanha de Fomento ao Aproveitamento Energético do Biogás no Brasil. Secretaria Nacional de Saneamento Ambiental. Ministério das Cidades, Deutsche Gesellschaft für Internationale Zusammenarbeit GmbH (GIZ). Brasília, 2015.

QIAN, Y.; SUN, S.; JU, D.; SHAN, X.; LU, X.. Review of the state-of-the-art of biogas combustion mechanisms and applications in internal combustion engines. Renewable and Sustainable Energy Reviews, v.69, p.50-58, 2017. DOI: https://doi.org/10.1016/i.rser.2016.11.059

RAJENDRAN, K.; KANKANALA, H. R.; LUNDIN M.; TAHERZADEH, M. J.. Bioresource technology a novel process simulation model (PSM) for anaerobic digestion using Aspen Plus. Bioresource Technology, v.168, p.7-13, 2014. DOI: http://doi.org/10.1016/j.biortech.2014.01.051

RODIONOVA, M. V.; POUDYAL, R. S.; TIWARI, I.; VOLOSHIN, R. A.; ZHARMUKHAMEDOV, S. K.; NAM, H. G.; ZAYADAN, B. K.; BRUCE, B. D.; HOU, H. J. M.; ALLAKHVERDIEV, S. I.. Biofuel Production: Challenges and Opportunities. International Journal of Hydrogen Energy, v.42, n.12, p.8450-8461, 2017. DOI: https://doi.org/10.1016/j.ijhydene.2016.11.125

ROSSETTO, C.; SOUZA, S. N. M. D.; O. L. K.. Desempenho de motor-gerador de ciclo otto operado com gasolina e biogás proveniente de suinocultura. Brazilian Journal of Biosystems 
Engineering, v.8, n.1, p.34-42, 2014. DOI: https://doi.org/10.1017/CBO9781107415324.004

SINGHA, J.; SUHAG, M.; DHAKAC, A.. Augmented digestion of lignocellulose by steam explosion, acid and alkaline pretreatment methods: A review. Carbohydrate Polymers, v.117, n.6, p.624-631, 2015. DOI:

http://doi.org/10.1016/i.carbpol.2014.10.012

SUZUKI, A. B. P.; FERNANDES, D. M.; FARIA, R. A. P. F.; VIDAL, T. C. M.. Uso de biogás em motores de combustão interna. Revista Brasileira de Tecnologia Aplicada nas Ciências Agrárias, João Pessoa, v.4, n.1, 2011.
TESISAT. Biogás Utilization and Production Process. 2017

WILLIAMS, C.; PORTER, P.. BIOEN: Sustainable Bioenergy. Introduction to anaerobic digestion. Energy Independence, Bioenergy Generation and Environmental Sustainability online Training Center. National Institute of Food and Agriculture, 2012.

WOLF, D.; SMEERS, Y.. The gas transmission problem solved by an extension of the simplex algorithm. Management Science, v.46, n.11, p.1454-1465, 2000. DOI: http://doi.org/10.1287/mnsc.46.11.1454.12087

A CBPC - Companhia Brasileira de Produção Científica (CNPJ: 11.221.422/0001-03) detém os direitos materiais desta publicação. Os direitos referem-se à publicação do trabalho em qualquer parte do mundo, incluindo os direitos às renovaç̃̃es, expansões e disseminações da contribuição, bem como outros direitos subsidiários. Todos os trabalhos publicados eletronicamente poderão posteriormente ser publicados em coletâneas impressas sob coordenação da Sustenere Publishing, da Companhia Brasileira de Produção Científica e seus parceiros autorizados. Os (as) autores (as) preservam os direitos autorais, mas não têm permissão para a publicação da contribuição em outro meio, impresso ou digital, em português ou em tradução. 